\title{
Faculty Members Have a Story to Tell: Communicating the Value of Colleges and Universities
}

\author{
Libby V. Morris ${ }^{1}$
}

Published online: 5 December 2017

(C) Springer Science+Business Media, LLC, part of Springer Nature 2017

For several years now, the value of college and its impact have been questioned. Front page stories detail student misbehaviors, loan defaults, faculty and administrator misdeeds, and athletic scandals. Collectively, these stories grab public attention and create the impression that higher education is off course and declining in value. However, thousands of instances reflecting a positive impact are overlooked; and those stories remain untold. As educators, we need to seek to restore confidence in our processes, outcomes, and impact. We must clearly delineate our contributions to the cultural fabric of society, our importance to the economy (i.e. workforce) and national security, and our specific contribution to the complex task of educating individuals. I am not talking about hiring more marketing professionals, launching branding efforts, or designing improved websites. Rather, the faculty, the core of the academic enterprise, can mobilize to communicate what the academic content of programs is; what students learn and how they learn it; how their research contributes in so many ways; and how their own programs, research and college make a difference.

Why now? A recent article in TRUST by the Pew Charitable Trust hammered this urgent need home. In the fall 2017 issue (vol. 19), the divide between U.S. conservatives and liberals on the issue of the effect of colleges on the "way things are going in the country" was startling. While $72 \%$ of Democrats saw the impact of college as positive, only $35 \%$ of Republicans did so. Among Republicans a positive perception of college had declined for those with and without college degrees by comparison to two years earlier.

What has gone right? The good news is that most of those interviewed felt that colleges help people get a good job and that a college degree is important. Both Democrats and Republicans thought that their personal college experience was valuable. So, we have some building blocks here; degrees and "good" jobs are valued. Colleges are seen as a source of individual skill and knowledge development. Plus, the majority of those who have attended college cite a good experience. However, there is still a deep

Libby V. Morris

lvmorris@uga.edu 
divide between those who believe that the college experience has a positive effect and those who believe that it has a negative effect.

What can we do? As faculty members it is probably beyond our abilities (as able as we are!) to change the perception of higher education overall, but I think that we must ask ourselves the following question. "What can we do to move the needle on the public's perception of college as having a negative influence on the way things are going in the country?" Faculty members have a story to tell at the course, program, and institutional levels. These stories show the positive impact on degree attainment, job creation and employment, and the impact of new knowledge.

Three suggestions come to mind:

- Define and expand your audience. Faculty members tend to think of their instructional audience as students and their research audience as other scholars and sometimes practitioners or policymakers. Who needs to understand what you do, beyond the usual suspects? I know that many programs feature an extensive outreach and service orientation (e.g., agriculture, public health, social work); and these units communicate beyond the cadre of administrators, academics, and students with whom we regularly interact. It is time for all of us as individuals and program representatives to define a larger audience and to reach out to that audience. In doing so, we can listen to our constituents. What are they saying? What do they want? What story do we as faculty members want to tell?

- Explain your curriculum, your instructional format, and service activities. Students are not attending their mother's institution any more. Have we engaged our public to convey the contemporary complexity in teaching and learning, ranging from face-to-face to hybrid, from service learning to study abroad? Can you succinctly explain what your program offers and its outcomes? Where do the alumni go? What special expertise do they develop? The overwhelming majority of students attend college in-state; so direct contact with alumni (beyond asking for money!), opinion leaders and legislators, and civic and cultural clubs can make a difference in perceptions and perhaps program support on a variety of levels. These talks do not have to be boring. We are doing exciting things.

- Share your own research and professional expertise with the general public. Three audiences come to mind when research is communicated: other scholars through journal articles and professional academic meetings, policy makers and practitioners, and the general public. Can you write about and talk about your research in an accessible way? If so, who would be the target of your work (see the first suggestion)? How many of the authors published in Innovative Higher Education have blogged about their research or presented their findings and recommendations to a defined public? If your findings are important to scholars, don't they have some relevance in the public domain? Can you draft a two-page overview for distribution or as talking points at meetings of stakeholders and other potentially interested parties? Remember to keep the format short, focus on the key issues, engage the audience with questions, seek out their ideas and interests, and drop the jargon.

Just as I started to write this editorial, what should appear in my inbox but an announcement of a new course to be offered at the University of Georgia titled "Communicating Physical Science topics to Diverse Audiences." I hope you will send me your examples of how you communicate your research and expertise to a general audience. Are you telling your stories? How do you as a faculty member communicate the value and impact of your courses and 
programs? I believe that faculty members can affect the discussion and influence public opinion about higher education. Faculty members are at the core of all that we do; they should be the messengers. I look forward to the dialogue! 